\title{
Okullaşma Sürecinde Uzaktan Evde Eğitime Geçiş
}

\author{
ELIF DAŞCI SÖNMEZ \\ elifdasci89@gmail.com \\ ORCID ID: 0000-0002-6029-5934
}

\author{
NeCATI CEMALOĞLU** \\ necem@gazi.edu.tr \\ ORCID ID: 0000-0001-7753-2222
}

Öz: Uzaktan eğitim uygulamaları ile birlikte öğrenci ve öğretmenlerin ayn veya farkh zamanlarda mekândan bağımsiz olarak öğrenme süreçlerini gerçekleştirmesi mümkün olmaktadır. Bu araştırmanın amacı, okullaşma sürecinde uzaktan evde eğitime (homeschooling) geçiş sürecini incelemektir. Bu amaca yönelik olarak, öncelikle uzaktan eğitimin tarihsel gelişimine yönelik literatür ele alınmıştır. Daha sonra Dünya'nın maruz kaldığı Covid-19 pandemisi koşullarında MEB’in izlediği politika ve stratejilere yer verilmiş ve bu süreçte "sosyal mesafe"ye en uygun yöntem olarak tercih edilen ve uzaktan eğitimin bir türü olan çevrim içi öğrenme bağlamında değerlendirmeler yapılmıştır. Bu öğretim türünün çeşitli faktörlere ve eğitim kademelerine göre etkisi incelenerek, çevrim içi eğitime ilişkin yeterlikler ifade edilmiş ve dezavantajl aile çocuklarının eğitime erişimi konusundaki endişeler ele alınmıştır. Ayrıca bu çalışmada, pandemi dönemindeki öğrenme deneyimlerinin eğitim sistemleri üzerinde kalıcı bir etkisi olabileceği ve gelecekte okullarda yüz yüze eğitim hizmetlerinin kesintiye uğraması durumunda, öğrenmenin sürekliliğini sağlamak için uzaktan öğrenmeye yumuşak bir geçiş sağlamanın gerekli olduğuna yönelik çıkarımlar yapılmıştır.

Anahtar kelimeler: Uzaktan eğitim, Evde eğitim, Covid-19 pandemisinde eğitim,

Koronavirüs

\section{Giriş}

Birçok ülke, Covid-19 pandemisi nedeniyle eğitim-öğretim faaliyetlerine ara vermişlerdir. ${ }^{1}$ Dünya genelinde, 100 'den fazla ülkedeki okullar, yaklaşık 1 milyardan daha fazla çocuğun eğitimini etkileyen koronavirüsün yayılımına karşı koruma sağlamak amacıyla yüz yüze eğitim yapmamıştır. Bu süreçte çocukların evde eğitim görmesi nedeniyle, eğitim yaklaşımları yeniden sorgulanmaya başlanmıştır. Covid-19 ile başa çıkma sürecinde eğitim otoriteleri, uzaktan eğitim ve diğer dijital çözümleri en iyi yol olarak nitelendirmektedirler. ${ }^{2}$ Bu bağlamda, öğretmenlerin

\footnotetext{
${ }^{*}$ Dr., Millî Eğitim Bakanlığı.

${ }^{* *}$ Prof. Dr., Gazi Üniversitesi, Gazi Eğitim Fakültesi, Eğitim Bilimleri Bölümü.

1 "Education: From Disruption to Recovery", Birleşmiş Milletler Eğitim, Bilim ve Kültür Örgütü (UNESCO), erişim 13 Temmuz, 2020, https://en.unesco.org/covid19/educationresponse.

${ }^{2}$ Juan Manuel Moreno ve Lucas Gortazar, "Schools' Readiness for Digital Learning in the Eyes of Principals:
} 
pandemi süresince kullandıkları yeniliklerin kalıcı bir değişime yol açabileceğine ve teknolojinin gelecekte okullarda daha büyük bir rol oynayacağına yönelik bakış açıları giderek yaygınlaşmaktadır. ${ }^{3}$

Uzaktan eğitim süreçlerinin uygulamaları, pandemi öncesine dayanmaktadır. Uzaktan eğitimin bir türü olarak kabul edilen "evde eğitim" (homeschooling) hareketi, Amerika'da (ABD) 1960'lı yıllarda başlamış ve daha sonra hızlı bir şekilde yaygınlaşmıştır. ${ }^{4}$ Ev okulu olarak da bilinen evde eğitim yaklaşımında, çocuklar okul müfredatına yönelik eğitimi aileleri veya öğretmenler eşliğinde takip etmektedirler. Dolayısıyla aileler önemli bir sorumluluğa sahiptir. Çocukların akademik, sosyal ve ahlaki eğitimleri evde aile desteğiyle gerçekleşmektedir. ${ }^{5}$ Geçmişte tercihe bağlı bir eğitim türü olarak veya dezavantajlı grupların eğitime erişimini sağlamak amacıyla farklı kullanımları söz konusu olsa da bu süreçte "sosyal mesafe" kuralına en uygun eğitim yöntemi olarak karşımıza çıkmaktadır. ${ }^{6}$ Dolayısıyla tarihsel süreç içerisinde uzaktan eğitim kurum ve yöntemlerinde gelişme sağlayan toplumlar, Covid-19 pandemisi döneminde eğitime erişim yöntemlerinde daha avantajlı bir konumda yer almaktadırlar. Ancak pandemi sürecinde uygulanan acil uzaktan eğitim (emergency remote education), zorunluluk nedeniyle ihtiyaca yönelik geçici çözümler içermektedir. ${ }^{7}$ Bu noktada, uzaktan eğitim sistemleri açısından zorluk yaşayan ülkeleri desteklemek için bazı uluslararası kuruluşlar çeşitli girişimlerde bulunmuşlardır.

UNESCO, Covid-19 pandemisi sürecinde ülkelerin uzaktan eğitimlerini planlamasına yönelik on öneri yayınlamıştır. Bunlar: (I) Hazırlık durumunun incelenmesi ve en uygun araçların (entegre dijital öğrenme platformları, video dersler, kitlesel açık çevrimiçi kurslar, radyolar ve televizyonlar vb.) seçilmesi, (II) kapsayıcı (engelli veya düşük gelirli ailelerden gelenleri de dahil) olması, (III) veri gizliliği ve güvenliğinin korunması, (IV) öğretimden önce psiko-sosyal zorluklara yönelik çözümlere öncelik verilmesi, (V) zaman çizelgesinin planlanması, (VI) öğretmenlere ve ailelere dijital araçların kullanımı ile ilgili destek sağlanması, (VII) uygun yaklaşımların harmanlanması ve uygulama-platform sayısının sınırlanması, (VIII) kuralların geliştirilmesi ve öğrencilerin öğrenme sürecinin izlenmesi, (IX) birim sürelerinin öğrencilerin öz-düzenleme becerilerine göre belirlenmesi ve (X) toplu-

An Analysis from PISA 2018 and Its Implications for the COVID19 (Coronavirus) Crisis Response”, World Bank Blogs, https://blogs.worldbank.org/education/schools-readiness-digital-learning-eyes-principals-analy sis-pisa-2018-and-its, (erişim 21.07.2020).

${ }^{3}$ Douglas Broom, "The World Economic Forum-Homeschooling During the Coronavirus Pandemic Could Change Education Forever, Says the OECD”, https://www.weforum.org/agenda/2020/04/coronavirus-homeschooling-technology-oecd/, (erişim 13.07.2020).

${ }^{4}$ Isabel Lyman, "Homeschooling: Back to the Future?", Policy Analysis, 294 (1998), s.5.

${ }^{5}$ Ed Collom, "The Ins and Outs of Homeschooling: The Determinants of Parental Motivations and Student Achievement”, Education and Urban Society, 37/3 (2005), s.328.

${ }^{6}$ Fernando M. Reimers, "What the Covid-19 Pandemic Will Change in Education Depends on the Thoughtfulness of Education Responses Today", https://www.worldsofeducation.org/en/woe_homepage/woe_detail/ $16727 / \% \mathrm{E} 2 \% 80 \% 9 \mathrm{C}$ what-the-covid-19-pandemic-will-change-in-education-depends-on-the-thoughtfulness -of-education-responses-today\%E2\%80\%9D-by-fernando-m-reimers, (erişim 16.07.2020).

${ }^{7}$ Erdal Bay, "Covid-19 Sürecinde Yüz yüze Eğitim Sorunu", https://www.haber342.com/koseyazisi/covid-19surecinde-yuz-yuze-egitim-sorunu-yazisi-393.html, (erişim 21.09.2020). 
luklar (öğretmen, ebeveyn ve okul yöneticisi) oluşturulması ve bağlantının geliştirilmesi olarak sıralanmaktadır. ${ }^{8}$ Ancak öğrencilerle yüz yüze temas eksikliği, öğretmek yerine not vermeye odaklanma ve teknoloji veya ihtiyaç duyulan pedagojik stratejilerle ilgili sınırlı uzmanlık, eğitmenlerin çevrimiçi öğretme konusundaki isteksizliğine neden olabilmektedir. ${ }^{9}$

Uzaktan eğitimin en yaygın kullanılan türlerinden biri olan online (çevrim içi) öğrenme yönteminin bir kuruma dâhil edilmesi veya yeni bir uzaktan eğitim kurumu kurulması, öğretim ve diğer kaynakların kullanımında önemli değişiklikler yapmak anlamına gelmektedir ve bu politikadan sorumlu kişilerin dikkatle ele almasını gerektiren süreçler mevcuttur. Özellikle hem kurumsal hem de hükümet düzeyindeki politika yapıcılar sadece uzaktan eğitim hizmetini nasıl sunacaklarını değil, neden sunacaklarını da dikkate almalıdırlar. Bunun için belirtilen nedenler; eşitlik açısından öğrenme ve öğretime erişimi arttırmak, iş gücünün becerilerini güncelleme firsatları sunmak, eğitim kaynaklarının maliyet etkinliğini artırmak, mevcut eğitim yapılarının kalitesini ve kapasitesini artırmak, hedef gruplar için acil durum eğitimi sağlamak, eğitimin iş ve aile hayatı ile birleşimini sunmak ve eğitim deneyimine uluslararası bir boyut katmak şeklinde sıralanmaktadır. ${ }^{10}$

$\mathrm{Bu}$ araştırmanın amacı, okullaşma sürecinde uzaktan evde eğitime (homeschooling) geçiş sürecini incelemektir. Tüm dünyada Covid-19 pandemisi ile birlikte uzaktan evde eğitim uygulamalarının önemi giderek artmaktadır. Ancak bu uygulamalara ülkelerin hâlihazırdaki alt yapılarının yeterlik durumları birbirinden farklılık göstermekte, eğitime erişim veya erişilen eğitimin niteliği konusunda endişe uyandıran durumlar ortaya çıkabilmektedir. Bu araştırmada, söz konusu literatür incelenmiş ve dikkat geçen ve önemli noktalar derlenmiştir.

\section{Uzaktan Eğitim ve Tarihsel Gelişimi}

Uzaktan eğitim, öğrenme sürecinde sağladığı esneklik ve özgürlük sayesinde eğitim ortamlarında popüler bir paradigma haline gelmiştir. ${ }^{11}$ Uzaktan eğitim kursları, öğrenme hedefleri, içerik temaları, bilgi sunumları, vaka çalışmaları, görseller (resim, video vb.), alıştırmalar, projeler ve testler gibi unsurlardan oluşmalıdır. ${ }^{12}$ Bu bağlamda özellikle çevrim içi eğitim ortamları, öğrencilerin birden fazla öğrenme etkinliğine sahip olma ve aynı zamanda çeşitli kaynaklara ulaşma firsatına sahip oldukları bir atmosfer olarak tanımlanmaktadır. ${ }^{13}$ Uzaktan eğitimde çevrim içi eğitim araçları sayesinde, öğretmenler ve öğrenciler, öğretmeye ve öğrenmeye

\footnotetext{
8 UNESCO, "Uzaktan Eğitim Çözümlerini Planlamak için 10 Öneri”, erişim 13 Temmuz, 2020, http://www.unesco.org.tr/Home/AnnouncementDetail/1453.

${ }^{9}$ Maureen S. Andrade, "Teaching Online: A Theory-based Approach to Student Success", Journal of Education and Training Studies, 3/5 (2015), s.1.

${ }^{10}$ Michael G. Moore ve Greg Kearsley, Distance Education: A Systems View of Online Learning, Canada: Wadsworth Publishing, 3. bs., 2012, s.8.

${ }^{11}$ Hitendra Pillay, Kym Irving ve Megan Tones, "Validation of the Diagnostic Tool for Assessing Tertiary Students' Readiness for Online Learning”, High Education Research \& Development, 26/2 (2007), s.217.

${ }^{12}$ Moore ve Kearsley, Distance Education, s.211.

${ }^{13}$ Anthony R. Artino, "Online Learning: Are Subjective Perceptions of Instructional Context Related to Academic Success”, The Internet and Higher Education, 12/3 (2009), s.117.
} 
ayırdıkları zamanın tamamında veya çoğunda farklı ortamlarda bulunmaktadırlar. ${ }^{14}$ Günümüzde de oldukça önemli bir yere sahip olan uzaktan öğrenme yaklaşımları, tarihsel süreçte teknolojik imkânlara paralel bir gelişim göstermiştir.

1892'de William Rainey Harper, Chicago Üniversitesi'ne atandığında, yetişkinlere öğrenme fırsatı sağlamak için posta sistemini kullanarak eşitlikçi bir uygulamayı hayata geçirmiştir. Bunun için bir mektupla öğretim programı kurarak başkanlık görevine başlamış, böylece dünyanın ilk resmi uzaktan eğitim programı hayata geçirilmiştir. ${ }^{15}$ Uzaktan eğitim 1980'lerin başından itibaren uluslararası düzeyde çarpıcı bir büyüme yaşamıştır. Geleneksel eğitimin bir alternatifi olarak uzaktan eğitimin amacı, derece veren programlar sunmak, gelişmekte olan ülkelerde okuma yazma oranını artırmak, ekonomik büyüme için eğitim fırsatları sağlamak ve zengin bir müfredat içeriği sunmaktır. ${ }^{16}$

Finlandiya'da ilk mektupla öğretim 1908'de başlamıştır. İlk ve orta dereceli okullarda ve gönüllü yetişkin eğitimlerinde radyo ve televizyon destekleme amaçlı kullanılmıştır. 1980'lerde, Nokia gibi şirketlerin yüksek teknolojide inovasyon başarısıyla, bazı Fin üniversiteleri sesli ve görüntülü konferans kullanmaya istekli hale gelmiştir ve o yıllarda yeni içerik oluşturma ve öğretim süreçleri geliştirme konusunda güçlü bir istek oluşmuştur. Ayrıca, uzaktan mesleki gelişim amacıyla diğer ülkelerdeki kurumlarla iş birliği yapma girişimleri başlamıştır. ${ }^{17}$

1972'de İspanya'da kurulan erken dönem ulusal uzaktan eğitim üniversite sistemlerinden biri olan "Universidad Nacional de Educacion a Distancia" (UNED) hala eğitime devam etmektedir. 28 farklı eğitim programı sunan UNED’in öğretim materyalleri arasında temel akademik ve idari talimatları içeren bir öğrenci kılavuzu, Web materyalleri, haftalık radyo ve televizyon programlarına erişim mevcuttur. Çeşitli ülkelerde merkezleri bulunan sistemde, lisans derslerine giriş koşulları geleneksel üniversitelerdekiler ile benzerdir, ancak bu önkoşulları sağlamayanlar için hazırlık programı uygulanmaktadır. ${ }^{18}$

Almanya-Hagen'de 1974'te kurulmuş olan FernUniversitat, kamu uzaktan eğitim üniversitesidir ve beş fakülte ile hizmet vermektedir: Kültür ve Sosyal Bilimler Fakültesi, Matematik ve Bilgisayar Bilimleri Fakültesi, Psikoloji Fakültesi, İktisat Fakültesi ve Hukuk Fakültesi. Ders içerikleri, interaktif CD-ROM'lar ve DVD'ler gibi öğretim materyalleri aracılığıyla öğrencilerin adreslerine posta yoluyla veya internet üzerinden iletilmektedir. Ayrıca ödevler çevrimiçi olarak teslim edilmektedir. ${ }^{19}$

\footnotetext{
${ }^{14}$ Moore ve Kearsley, Distance Education, s.1.

${ }^{15}$ Moore ve Kearsley, Distance Education, s.25.

${ }^{16}$ Charlotte N. Gunawardena ve Marina S. McIsaac, "Distance Education", Handbook of Research on Educational Communications and Technology, der., J. Michael Spector, M. David Merrill, Jan Elen ve M. J. Bishop, New York: Springer, 2014, s.356.

${ }^{17}$ Moore ve Kearsley, Distance Education, s.252.

18 "Oferta de Grados Universitarios Oficiales 2020/2021", Universidad Nacional de Educacion a Distancia (UNED), erişim 30 Haziran, 2020, http://portal.uned.es/portal/page?_pageid=93,1643102\&_dad=portal \&_schema=PORTAL.

19 "Fakultäten und Einrichtungen", FernUniversitat in Hagen, erişim 30 Haziran, 2020, https://www.fernunihagen.de/universitaet/fakultaeten-und-einrichtungen.shtml.
} 
Genel olarak, uzaktan eğitimin tarihsel gelişim süreci küresel koşullara göre beş aşamada ele alınmaktadır. Bunlar: (I) Mektupla öğretim (1720), (II) radyo ve televizyon yayınları (1925), (III) açı öğretim kurumları (1970), (IV) telekonferans (1980) ve (V) internet ve web (1990) olarak ifade edilmektedir. ${ }^{20}$ Günümüzde uzaktan eğitimin en popüler türlerinden biri "çevrim içi öğrenme"dir. Bu öğrenme deneyiminde öğrencilere teknoloji, çevrim içi kurs materyalleri ve etkileşimleri aracılığıyla içeriğin aktarımı sağlanmaktadır. ${ }^{21}$ Böylece geniş çeşitlilikteki öğrenci gruplarının eğitime erişimi sağlanabilmektedir. ${ }^{22}$

\section{Uzaktan Eğitimin Türkiye'deki Gelişimi}

Türkiye'de uzaktan eğitimin gelişim süreçleri, kullanılan teknolojiler ve alanı etkileyen önemli olaylar göz önüne alındığında şu şekilde sınıflandırılmaktadır: (I) Tartışma ve önerileri içeren kavramsal dönem (1923-1955), (II) mektupla öğretim dönemi (1956-1975), (III) radyo ve televizyon gibi görsel-işitsel araçlar dönemi (1976-1995) ve (IV) bilişim tabanlı internet-web aracılığı ile eğitim dönemi (1996devam etmektedir). ${ }^{23}$

Cumhuriyetin ilanı ile birlikte hızlı eğitim reformları çabasıyla 1924 yılında eğitimci John Dewey’in Türkiye'yi ziyareti sonrasında yazılan “Türk Eğitimi Üzerine Öneriler ve Rapor" (Report and Recommendation upon Turkish Education) başlıklı raporda kapsamlı görüşlerin yanı sıra yazışarak ve/veya mektupla öğrenmenin öğretmen eğitiminde kullanılabileceği önerisi yer almaktadır. Ayrıca gezici kütüphanelerin kurulması, bu kütüphanelerin yetişkin eğitimine açılması fikri de uzaktan eğitim felsefesinin temellerinden olan açıklık kavramına karşılık gelmektedir. ${ }^{24}$ Kavramsal düşünce sürecini başlatan bu olay, 1939'da ilk Milli Eğitim Şurasında yaygın eğitim konusunun tartışılması, 1941'de eğitsel radyo programlarının (Ziraat Takvimi, Evin Saati) hazırlanması ve 1951'de Öğretici Filmler Merkezi (ÖFM-bugünkü adıyla YEĞİTEK-Yenilik ve Eğitim Teknolojileri Genel Müdürlüğü) kurulması ile birlikte uzaktan eğitim uygulamalarına geçiş yapılmaya başlanmıştır. ${ }^{25}$

1953'te Millî Eğitim Bakanlığı'nın (MEB) 420-5-2300 sayılı kararı ile kurulan FONO Açık Öğretim Kurumu aracılığıyla yazışarak/mektupla yabancı dil eğitimi uygulaması başlamıştır. Bankacılık sektöründe de kullanılan mektupla uzaktan eğitim uygulamaları, Mektupla Öğretim Merkezi'nin MEB bünyesinde yer almasıyla birlikte yaygınlaşmıştır. ${ }^{26} 1975$ yılında lise ve dengi okul çıkışlı öğrencilere, modern eğitim teknolojisinin tüm gereklerini kullanarak öğretim olanağı sağlamak ve iki yıllık ön lisans eğitimi ile ara insan gücü kademesini yetiştirmek amacıyla Yaygın Yüksek Öğretim Kurumu (Yay-Kur) hizmete başlamış, 1979 yılına kadar varlığını sürdürmüştür. 1982'de uzaktan eğitim yoluyla eğitim vermek amacıyla

${ }^{20}$ Moore ve Kearsley, Distance Education, s.24.

${ }^{21}$ Andrade, "Teaching Online", s.1.

${ }^{22}$ Gunawardena ve McIsaac, "Distance Education", s.356.

${ }^{23}$ Aras Bozkurt, “Türkiye’de Uzaktan Eğitimin Dünü, Bugünü ve Yarını”, Açıköğretim Uygulamaları ve Araştırmaları Dergisi, 3/2 (2017), s.87-88.

${ }^{24}$ John Dewey, Jo Ann Boydston ve Ralph Ross, The Middle Works of John Dewey, Volume 13, 1899-1924: 1921-1922, Essays on Philosophy, Education, and the Orient, Southern Illinois University Press, 1983, s.3-4.

${ }^{25}$ Bozkurt, "Türkiye'de Uzaktan”, s.93.

${ }^{26}$ T.C. Resmî Gazete, Mektupla Öğretim Merkezi Kuruluşve Çalışma Yönetmeliği, sayı: 15252, 22.5.1975, Ankara: Başbakanlık Basımevi, s.18-19. 
Anadolu Üniversitesi bünyesinde Açı Öğretim Fakültesi kurulmuştur. ${ }^{27}$ Dünyanın en büyük uzaktan eğitim üniversitelerinden biri olan Anadolu Üniversitesi, örgün eğitimi yanı sıra aktif kayıtlı bir milyonu aşan açık öğretim öğrencisine, Eskişehir kampüsünde saha tasarımı ve üretimleri ile hala hizmet vermeye devam etmektedir. ${ }^{28}$

Bu gelişmelerin yanı sıra 1983 yılında Mesleki ve Teknik Açık Öğretim Okulu açılmıştır. ${ }^{29} 1991$ 'de Fırat Üniversitesi ilk uzaktan eğitim uygulamasını e-posta yoluyla yapmış, böylece öğrencilerin yüksek lisans eğitimlerini tamamlamaları için imkân sağlanmıştır. Televizyon aracılığıyla uzaktan eğitim imkânları genişletilmiştir. ${ }^{30}$ 1992'de MEB bünyesinde Açık Öğretim Lisesi kurulmuştur. Bu şekilde orta öğrenime devam edemeyen kişilere uzaktan eğitimlerini tamamlama ve diploma alma olanağ 1 tanınmıştır. ${ }^{31} 1996$ yılında Bilkent Üniversitesi'nde video konferans aracılığıyla bazı derslerin ABD'den yürütülmesi denemeleri yapılmış, Ortadoğu Teknik Üniversitesi (ODTÜ) Enformatik Enstitüsü’nde internet üzerinden uzaktan eğitim uygulamaları ve sertifika programları başlatılmıştır. ${ }^{32}$ Benzer uygulamalar İstanbul, Gazi, Sakarya ve Ahmet Yesevi Üniversitesi gibi bazı diğer üniversitelerde de görülmeye başlanmıştır. 2014'te Yükseköğretim Kurulu (YÖK) tarafından yükseköğretim kurumlarında uzaktan öğretime ilişkin usul ve esaslar belirlenmiştir. Yükseköğretim kurumlarının; ön lisans, lisans ve yüksek lisans düzeyinde birinci ve ikinci öğretim programlarındaki bazı derslerin uzaktan öğretim yoluyla verilmesine yönelik düzenlemeler yapılmıştır. ${ }^{33}$ Türkiye'nin uzaktan eğitimin bir türü olan çevrim içi eğitim alanında gösterdiği gelişmeler, Covid-19 pandemisi sırasında eğitim hizmetlerinin devam etmesi açısından büyük katkılar sağlamıştır.

\section{Türkiye'de Covid-19 Pandemisinde MEB'in İzlediği Politikalar, Stratejiler}

Yaklaşı 18 milyon öğrenci ve 1 milyon öğretmenin yer aldığı Türk Eğitim Sisteminde, Covid-19 salgını sürecinde, tüm eğitim paydaşlarının sağlı̆̆ını ve refahını gözeterek ve Bilim Kurulu'nun tavsiyelerine dayanarak okullarda yüz yüze eğitime ara verme kararı alınmıştır. Eğitim hizmetlerinin devamı için MEB tarafından çeşitli adımlar atılmıştır. Alternatif eğitim platformlarının önemli hale geldiği bu süreçte uzaktan eğitim, MEB'in hizmetlerini sürdürmesinde ve bu hizmetleri tüm eğitim paydaşlarına iletmesinde kilit bir unsur olmuştur. ${ }^{34}$ Uzaktan eğitim için ana platform olarak kullanılan EBA (Eğitim Bilişim Ağı), 2011-2012 akademik yılından

\footnotetext{
${ }^{27}$ T.C. Resmî Gazete, Yükseköğretim Kurumlan Teşkilâtı Hakkında Kanun Hükmünde Kararname, sayı: 17760, 20.7.1982, Ankara: Başbakanlık Basımevi, s.11.

28 "Kurumsal: Hakkında", Anadolu Üniversitesi, erişim 29 Temmuz, 2020, https://www.anadolu.edu.tr/uni versitemiz/kurumsal/hakkinda.

29 “Mesleki ve Teknik Açık Öğretim Okulu”, Millî Eğitim Bakanlığı (MEB), erişim 6 Temmuz, 2020, http:// www.hbo.gov.tr/OgrenmeFirsatlari/MTAO.

${ }^{30}$ Bozkurt, "Türkiye'de Uzaktan", s.100.

31 “Açık Öğretim Lisesi: Tarihçe”, MEB, erişim 29 Temmuz, 2020, http://aol.meb.gov.tr/www/okulumuz/ icerik/1.

${ }^{32}$ Bozkurt, "Türkiye’de Uzaktan”, s.102.

33 "Yükseköğretim Kurumlarında Uzaktan Öğretime İlişkin Usul ve Esaslar”, Yükseköğretim Kurulu (YÖK), erişim 29 Temmuz, 2020, https://www.yok.gov.tr/Documents/Kurumsal/egitim_ogretim_dairesi/Uzaktan_ ogretim/yuksekogretim_kurumlarinda_uzaktan_ogretime_iliskin_usul_ve_esaslar.pdf.

${ }^{34}$ Mahmut Özer, "Educational Policy Actions by the Ministry of National Education in the times of COVID19”, Kastamonu Education Journal, 28/3 (2020), s.1126.
} 
beri hizmet vermekte ve okul öncesinden lise seviyesine kadar, müfredat tabanlı videolar, belgeler, e-kitaplar, testler, etkinlikler dâhil olmak üzere çeşitli öğrenme materyallerini bulundurmaktadır. ${ }^{35}$ Uzaktan eğitim döneminde tüm eğitim içerikleri kademelere göre yapılandırılmış ve eğitim paydaşlarının hizmetine sunulmuştur. ${ }^{36} \mathrm{Bu}$ altyapının sürdürülebilir hale getirilmesi için EBA altyapısını geliştirmeye yönelik yatırımlar yapılmıştır. Ayrıca MEB tarafından, öğrencilerin EBA çevrim içi portalına erişimini desteklemek için Türkiye'nin önde gelen GSM (Global System for Mobile Communications) operatörleri ile iş birliği yapılarak, 8 GB'ye kadar öğrencilere ücretsiz internet erişimi sağlanmıştır. ${ }^{37}$

EBA ile eş zamanlı olarak, tüm videolar televizyondan öğrencilere TRT (Türkiye Radyo Televizyon Kurumu) aracılığıyla sunulmaya başlanmıştır. Bu sayede, evde internet bağlantısı olmayan öğrenciler uzaktan eğitim içeriklerine televizyon aracılığıyla erişebilmişlerdir. Kanal alternatifleri, farklı eğitim kademelerine yönelik içerikleri yayınlamışlardır. MEB yine de çevrim içi ve uzaktan eğitime erişimdeki olası eşitsizlikleri göz önünde bulundurarak, LGS (Liselere Geçiş Sınavı) içeriğini 8. sınıf müfredatının sadece yüz yüze eğitim görülen ilk dönemiyle sınırlı tutmuştur. 8. sınıftaki tüm öğrencilerin bu sınava otomatik kayıtları otomatik olarak MEB tarafından yapılmış, ancak sınava giriş zorunlu tutulmamıştır. ${ }^{38}$

MEB, UNESCO ile iş birliği yaparak öğretmenlere yönelik çevrim içi mesleki gelişim programı hazırlamış, çeşitli konulara odaklanan bu 17 program uzaktan eğitim yoluyla öğretmenlere sunulmuştur. Ayrıca uzaktan eğitim ile birlikte MEB, öğrencilerin ve velilerin psikolojik dayanıklılığını desteklemeyi amacıyla, onların duygusal sağlığını korumak için psikososyal rehberler hazırlamış ve bunları kamuoyu ile paylaşmıştır. ${ }^{39}$ Özel eğitim alan öğrenciler için işaret dili destekli eğitim materyalleri de EBA portalına eklenmiştir. Mesleki eğitim kurumları, üretim kapasitesinin artırılması ile birlikte maske, önlük, tulum, temizlik malzemeleri ve solunum cihazları gibi bazı kritik toplumsal ihtiyaçların üretim kaynağı haline gelmiştir. ${ }^{40}$

2020 Ağustos ayında Milli Eğitim Bakanı Ziya Selçuk'un yaptı̆̆ı açıklamaya göre, 1,5 milyon çocuk uzaktan eğitime erişim ile ilgili sorun yaşamaktadır. Yani Türkiye'deki öğrencilerin yaklaşık \%8'i uzaktan eğitimden faydalanamamaktadır. Bu durumda olan her bir çocuğa Bakanlık tarafından 17 kitaptan oluşan özel bir set ulaştırılmakta ve 5 bin 200 EBA destek noktası kurulmaktadır. Ülkemizde 21 Eylül 2020 'de yüz yüze eğitimin küçük sınıflarla başlaması planlanmaktadır. Ancak veliler riskli görmesi durumunda çocuğunu okula göndermeme tercihinde bulunabileceklerdir. Ayrıca internet paketi olmayan çocukların eğitimle ilgili kotalarının iki katına çıkarılacağı belirtilmiştir. ${ }^{41}$

\footnotetext{
35 “EBA Nedir?”, Yenilik ve Eğitim Teknolojileri Genel Müdürlüğü (YEĞİTEK), erişim 24 Temmuz, 2020, http://www.eba.gov.tr/\#/anasayfa.

36 Yelkin Diker Coşkun, "Eğitimin İçeriği: Eğitim İzleme Raporu 2020", Eğitim Reformu Girişimi, https://www.egitimreformugirisimi.org/egitim-izleme-raporu-2020-egitimin-icerigi/. (erişim 01.11.2020).

${ }^{37}$ Özer, "Educational Policy", s.1127.

${ }^{38}$ Özer, "Educational Policy", s.1128.

39 "Koronavirüs Travmasına Karşı Psikososyal Destek Rehberleri”, MEB, erişim 24 Temmuz, 2020, http:// www.meb.gov.tr/koronavirus-travmasina-karsi-psikososyal-destek-rehberleri/haber/20605/tr.

${ }^{40}$ Özer, "Educational Policy", s.1128.

41 "Bakan Selçuk canlı yayında açıkladı! Uzaktan eğitim nasıl olacak?”, Milliyet, 29 Ağustos, 2020,
} 


\section{Teknoloji Destekli Eğitim Yöntemleri}

İnternet teknolojisinin öğretim uygulamalarına entegrasyonunu tanımlamak için kullanılan yöntemler, bu konudaki dil çeşitliliğini yansıtmaktadır: Teknoloji aracılığıyla öğrenme, dağıtılmış/uzaktan öğrenme, hibrit öğrenme, entegre dağıtılmış öğrenme ortamları, harmanlanmış öğrenme, bilgisayar aracılığıyla konferans, telematik, çevrim içi öğrenme, açık ve esnek öğrenme, e-öğrenme, sanal öğrenme. ${ }^{42}$ İsimleri birbirinden farklılık gösterse de uzaktan eğitimde öğretmenler ve öğrenciler, genellikle farklı ortamlarda olduklarından, birbirleriyle etkileşim kurmak için iletişim teknolojisine ihtiyaç duymaktadırlar. ${ }^{43}$

Uzaktan eğitimin en yaygın kullanımları olarak karşımıza çıkan $e$-öğrenme ve çevrim içi öğrenme kavramları, herhangi bir yerde ve/veya zamanda, öğrenme ve öğretme anlamında kullanılmaktadır. Bu kullanımdaki "e" ön eki elektronik anlamına gelmekte ve genellikle internetin kullanıldığı çevrim içi eğitimi ifade etmektedir. İletişimde kullanılan teknolojik cihaza bağlı olarak, aynı zamanda farklı yerdeki öğretmen ve öğrenci iletişimi senkron öğrenmeyi; farklı zamanda farklı yerdeki iletişimi ise asenkron öğrenmeyi ifade etmek için kullanılmaktadır. Bazen uzaktan eğitim ile eşanlamlı olarak kabul edilen bir başka terim, her yerde ve her zaman kullanılabilirliğini karakterize eden dağıtılmış öğrenme (distributed learning)dir. ${ }^{44}$ Tüm bu teknolojileri başarılı bir şekilde kullanmak için öğretmenler, teknolojilere özgü farklı tasarım ve mesajlaşma tekniklerini bilmek ve etkili bir şekilde uygulamak durumundadirlar. ${ }^{45}$

Teknoloji destekli eğitim yöntemleri tasarlanırken sistemin iyi yapılandırılması ve öğrenme çıktılarının açıkça belirtilmesi çok önemlidir. Her bir öğrenme çıktısı, bir üniteye karşılık gelecek şekilde tasarlanmalı ve hedef kitlenin katılımı bu çıktılara göre planlanmalıdır. Kurs materyalleri içerik ile bütünlük göstermeli, katılımcıların daha sonra tekrarına olanak sağlamalıdır. Çeşitli uyarıcı ve teşvik edici materyaller, farklı geçmişe sahip öğrenci grupları için tasarıma eklenmelidir. Mümkünse öğrencilerin ilgilerine uygun açık uçlu problem durumları yapılandırılmalıdır. Geri bildirim ve değerlendirmeler düzenli bir şekilde yapılmalıdır. ${ }^{46}$

\section{Çevrim İçi Eğitimin Değişik Faktörlere Göre İncelenmesi}

Uzaktan eğitimin tercih edilme nedenleri ekonomik, sosyal, kültürel, eğitsel ve teknolojik alt yapı faktörlerine göre değişiklik göstermektedir. Dünyanın İngiltere, İspanya, Hindistan ve Türkiye gibi farklı ülkelerinde üniversitelerin bünyesinde uzaktan öğretimin ortaya çıkışında, öğrenci başına düşen ortalama maliyete bağlı olarak ölçek ekonomileri sorumlu görülmektedir. Ekonomik açıdan yüksek sabit maliyetleri azaltmak ve aynı zamanda daha büyük bir öğrenci nüfusuna hizmet

\footnotetext{
https://www.milliyet.com.tr/siyaset/son-dakika-milli-egitim-bakani-ziya-selcuktan-uzaktan-egitim-aciklama si-6292822, (erişim 9 Eylül, 2020).

${ }^{42}$ Heather Kanuka ve Dianne Conrad, “The Name of the Game: Why Distance Education Says It All”, Quarterly Review of Distance Education, 4/4 (2003), s.385.

${ }^{43}$ Michael Simonson, Susan Zvacek ve Sharon Smaldino, Teaching and Learning at a Distance: Foundations of Distance Education, Charlotte, North Carolina: Information Age Publishing, 7. bs., 2019, s.143.

${ }^{44}$ Moore ve Kearsley, Distance Education, s.2.

${ }^{45}$ Moore ve Kearsley, Distance Education, s.1.

${ }^{46}$ Moore ve Kearsley, Distance Education, s.120-121.
} 
ederek ölçek ekonomilerinden yararlanmak için içerik üretimini paylaşma eğilimleri yaygınlaşmaktadır. Hatta günümüzde uzaktan eğitim yalnızca üniversitelerin tekelinde değildir. ${ }^{47}$ Küresel bir eğitim piyasasında uzaktan eğitim programlarının ihracatı giderek önem kazanmaktadır. Ancak, eğitim programlarını başka bir kültürel bağlamda satmak, sadece İngilizce'ye çeviri meselesi değildir. İçeriklerde yer alan görüntüler, kullanılan dil, renkler ve düzenleme kalıpları, farklı sosyal ve kültürel göstergelere uygun olarak yeniden yapılandırılmalıdır. ${ }^{48}$

Evde eğitimin ek maliyetleri vardır. Kullanılabilir birçok ücretsiz kaynak olsa da ders kitapları, kâğıt, sanat malzemeleri, bilgisayarlar, yazılım ve diğer ev okulu araçları gibi evde eğitim malzemeleri edinilmesi gerekmektedir. Bu yaklaşımda, dikkatli bütçeleme ve zaman yönetimi becerileri aileler için çok önemlidir. Çocuk, artık devlet okulu ortamında olmayacağından ve tüm öğrenimler evde gerçekleşeceğinden, ailenin yaşam tarzı ve temposunda da değişiklikler olacaktır. Günlük ev alışkanlıklarının evde eğitim planı ile koordineli olarak programlanması gerekecektir. Evde eğitimin en büyük dezavantajlarından biri, sosyalleşmesinin olmaması ya da insanlarla nasıl etkileşim kuracağının bilinmemesi durumudur. ${ }^{49}$ Evde eğitim aynı zamanda bir çocuğun yaş grubundaki çok sayıda çocukla daha az günlük etkileşim anlamına gelmektedir. Aslında bir açıdan, ev okulları, daha zayıf akademik performansa ve daha düşük benlik saygısına bağlı akran baskısı ve zorbalığa maruz kalmayı engellemektedir. ${ }^{50}$ Ev okullarında çocukların akranlarıyla organize spor ve diğer etkinliklere katılmalarına daha az zaman ayrılabilir. Ancak bu durum, akranlarına erişimi olmadığı, spor yapma veya ailenin dışındaki kişilerle sosyal olarak etkileşim kurma yeteneği olmadığı anlamına gelmez. Aslında, ev okullarında çocuklar genel olarak devlet okulundakinden daha geniş bir yetişkin grubu (özellikle profesyoneller) ile sosyalleşebilmektedirler..$^{51}$

Covid-19 pandemisi nedeniyle, pek çok ülkede vatandaşlara evde kalma çağrısı yapılmasıyla, eğitime erişimin neredeyse tek yolu uzaktan çevrim içi eğitim olarak karşımıza çıkmaktadır. Çocukların evde eğitim almasının doğurabileceği sorunlardan bazıları teknoloji bağımlılı̆̆ı ve obezite olarak ifade edilebilir. Uzmanlar, özellikle Covid-19 pandemisi döneminde çocukların evde geçirdiği sürelerde teknoloji bağımlığına dikkat edilmesi gerektiğini belirtmektedirler. ${ }^{52}$ Okullara verilen ara ve uzaktan eğitime başlanmasıyla birlikte çocukların teknoloji kullanım sürelerindeki artışı dengelemek için velilere çocuklarıyla etkili iletişim kurmaları tavsiye edil-

\footnotetext{
${ }^{47}$ Wolfram Laaser, "Economics of Distance Education Reconsidered”, Turkish Online Journal of Distance Education, 9/3 (2008), s.122.

${ }^{48}$ D. Gies Klusemann, "Contextualization and Localization in e-Content Production" (Proceedings of the First International Conference on Educational Technology in Cultural Context, University of Joensuu, Finland, September 02-03, 2003).

${ }^{49}$ Christa L. Green ve Kathleen V. Hoover-Dempsey, "Why do Parents Homeschool? A Systematic Examination of Parental Involvement", Education and Urban Society, 39/2 (2007), s.272.

${ }^{50}$ Stacey Bielick, Kathryn Chandler ve Stephen P. Broughman, Homeschooling in the United States: 1999 (NCES 2001-033), Washington, DC: National Center for Education Statistics U.S. Department of Education, 2001, s.10.

51 "Homeschooling Pros and Cons", Calvert Eğitim, erişim 2 Ağustos, 2020, https://www.calverteducation. com/should-i-homeschool/homeschooling-pros-and-cons.

${ }^{52}$ Emrah Gökmen, "Evde Kalınan Zaman İçerisinde Teknoloji Bağımlılığa Dikkat”, https://www.aa.com.tr/ tr/bilim-teknoloji/evde-kalinan-zaman-icerisinde-teknoloji-bagimliliga-dikkat-/1786067, (erişim 9.9.2020).
} 
mektedir. Bu durumun kaygı ve depresyon gibi travmaları engelleyebileceğine dikkat çekilmektedir. Teknolojinin dengeli kullanılması gerektiği gibi dengeli beslenmeye de dikkat edilmesi gerektiği belirtilmektedir. ${ }^{53}$ Bireylerin evde kalma nedeniyle daha fazla yeme eğiliminde olduğu, obezite ile mücadele eden çocuklar ve ergenlerin, sağlıklı yaşam tarzı içinde olması gerekirken tecrit durumundan dolayı sağlıkları için elverişsiz bir ortamda kaldıkları ifade edilmektedir.

Covid-19 döneminde evde eğitim durumunun, hane içi şiddet riski altında olan kadın ve çocukları olumsuz yönde etkileyeceğine ilişkin endişeler, Avrupa Konseyi dâhil olmak üzere pek çok bilim insanı ve kurum tarafından dile getirilmektedir. 2020 Mart ayının sonunda dahi birkaç hafta içinde evde kalan kadın ve çocukların şiddete veya istismara uğrama riskinin arttığını bilinmektedir. ${ }^{54}$ Yani bazı çocuklar evde eğitim sürecinde şiddet failleriyle aynı evde kalma riskiyle karşı karşıya kalmaktadırlar.

\section{Çevrim İçi Eğitimin Eğitim Kademelerine Göre İncelenmesi}

Uzaktan eğitimin bir türü olan “evde eğitim” dünyanın çeşitli ülkelerinde tercih edilen bir yöntem olarak karşımıza çıkmaktadır. Tercih nedenleri ve kullanılan eğitim kademeleri de birbirinden farklılaşabilmektedir. Örneğin, araştırmalar kaliteli erken öğrenme deneyimlerinin çocuklar için kritik olduğunu vurgulamaktadırlar. Ayrıca anaokuluna devam eden öğrencilerin liseden mezun olma olasılığının daha yüksek olduğu ve okul terki oranlarının daha düşük olduğu belirtilmektedir. Tüm kademelerde olduğu gibi okul öncesinde de çevrim içi eğitimin erişim ve maliyet gibi ciddi sorunları çözme potansiyeline sahip olduğu belirtilmektedir. ${ }^{55}$ Ancak uzmanlar, 2-5 yaş arası çocukların günde bir saatten fazla ekran önünde vakit geçirmelerini önermemektedir. ${ }^{56}$

İlköğretim ve ortaöğretim kademelerinde, öğrencilerin sosyal ve duygusal gelişimi genel anlamda, okul deneyimlerinin önemli bir yönüdür. Bu nedenle öğrenciye yönelik hazırlık üzerinde dikkatlice düşünmek gerekmektedir. Çevrim içi ve yüz yüze eğitim tasarımının yapıldığı harmanlanmış bir yaklaşım benimsenerek bu tür endişeler azaltabilir. ${ }^{57}$ Bu kademelerde görev yapan öğretmenler için uzaktan eğitim programlarında müfredat içeriğinin tasarımında ve sunumunda yüz yüze sınıf öğretimi ile ilişkili olandan daha fazla esnekliğin sağlanması öngörülmektedir. ${ }^{58}$

\footnotetext{
${ }^{53}$ Marcene Robinson, "COVID-19 Lockdowns Worsen Childhood Obesity”, http://www.buffalo.edu/news/ releases/2020/06/009.html, (erişim 09.09.2020).

54 "COVID-19 Nedeniyle Alınan Evde Kalma Önlemleri, Kadın ve Çocuklara Karşı Şiddet Riskini Artırabilir", Avrupa Konseyi, erişim 9 Eylül, 2020, https://www.coe.int/tr/web/ankara/-/covid-19-and-isolation-at-homemay-increase-the-risk-of-violence-for-women-and-children.

${ }^{55}$ Jackie Mader, “Online Preschool: Does It Work?”, https://www.pbs.org/newshour/education/online-pro grams-are-filling-a-preschool-gap-experts-warn-its-no-substitute-for-face-to-face-learning, (erişim 5.8.2020).

56 Amerikan Pediatri Akademisi (The American Academy of Pediatrics), "Media and Young Minds", Pediatrics, 138/5 (2016), s.1.

${ }^{57}$ Anthony G. Picciano ve Jeff Seaman, K-12 Online Learning: A Survey of U.S. School District Administrators, USA: Babson Survey Research Group, 2007, s.19.

${ }^{58}$ Ravinder Rena, "Challenges in Introducing Distance Education Programme in Eritrea: Some Observations and Implications”, Turkish Online Journal of Distance Education, 8/1 (2007), s.195.
} 
Yükseköğretim düzeyinde öğretim üyelerinin, bir dersi yüz yüze ortam ile uzaktan öğretimle vermek arasında farklılıklar olduğunun bilincinde olması gerekmektedir. Uzaktan öğretim için seçilen bir dersin içeriklerinin neler olacağının saptanması, bu içeriklerin uzaktan öğretim ile verilebilecek hale getirilmesi görevi, öğretim elemanı ve ders içeriği geliştirme uzmanlarında aittir. ${ }^{59} \mathrm{Bu}$ programlarda öğretim tasarımlarına bilişsel çıraklık, işbirlikçi araştırma, eleştirel yansıtma ve probleme dayalı öğrenme gibi başarılı birçok yaklaşım kolayca uyarlanabilir. ${ }^{60}$ Lisansüstü uzaktan eğitimlerde de öğrenciye uygunluk kritik olmakla birlikte, bu kademedeki öğrenciler dahi çevrim içi bir kursa katılmaya hazır olma ve başarılı olma konusunda endişe duyabilmektedirler. ${ }^{61}$

\section{Çevrim İçi Eğitime İlişkin Yeterlikler}

Çevrim içi derslerin plan ve programcıları, derslerin yerlerini, zamanlarını, katılacak öğrencileri ve uzaktan öğretim araçlarını detaylı olarak planlamalıdırlar. ${ }^{62}$ Buna yönelik olarak, bir tasarım ekibi, uygun altyapıda derslerin bölümlerini bir deney grubu üzerinde pilot olarak test ederek, öğrencilerin her bir hedefi gerçekleştirmesinin ne kadar zaman alacağını belirleyebilecektir. Bu yöntemle öğrencilerin potansiyel okuma hızları ölçülebilecek ve alınacak geri bildirimlerle kursun her bölümü için gereken okuma sayfaları özelleştirilebilir hale gelecektir. ${ }^{63}$

Teknik ve kurumsal destek gibi faktörlerin yanı sıra çevrim içi öğrenme pedagojisi, bu tür öğrenme ortamlarının önemli bir parçasını oluşturmaktadır. ${ }^{64}$ Çevrim içi öğrenme programlarının etkili bir şekilde sunulması öğrenci odaklı bir yaklaşım gerektirmektedir. ${ }^{65}$ Öğretmenlerin ise önceden hazırlık yapmaları ve daha disiplinli olmaları gerekmektedir. ${ }^{66}$ İnterneti standart sınıf modelleri sunmak için kullanmaya çalışmanın ötesine geçmek gerekmekte ve bunun yerine eğitimi geliştiren bir "zenginlik" sunmak için interneti kullanma yollarını geliştirmeye odaklanmamız gerekmektedir. ${ }^{67}$ Diğer bir yandan, uygulayıcı yeterlikleri kadar içerik ve materyallerin uygunluğu da oldukça önemlidir. Uzaktan eğitimlerde uygun olmayan içerik ve yöntemlerin kullanılması, öğrenciler üzerinde olumsuz etkilere yol açabilmekte, öğrenme ilgilerini ve motivasyonlarını önemli ölçüde azaltabilmektedir. Uzaktan eğitim uygun şekilde kullanıldığında en az klasik öğretim kadar faydalı olabilmektedir. ${ }^{68}$

\footnotetext{
59 “ÜSUZEM (Uzaktan Eğitim Uygulama ve Araştırma Merkezi) Hakkında”, Üsküdar Üniversitesi, erişim 4 Ağustos, 2020, https://uskudar.edu.tr/tr/uzaktan-egitim-uygulama-ve-arastirma-merkezi-hakkinda.

${ }^{60}$ Van Weigel, "E-Learning and the Tradeoff between Richness and Reach in Higher Education", Change, 33/5 (2000), s.15.

${ }^{61}$ Picciano ve Seaman, K-12 Online, s.18.

62 "ÜSUZEM (Uzaktan Eğitim Uygulama ve Araştırma Merkezi)-Hakkında”.

${ }^{63}$ Moore ve Kearsley, Distance Education, s.211.

${ }^{64}$ Ronald Phipps ve Jamie Merisotis, Quality on the Line: Benchmarks for Success in Internet-Based Distance Education, Washington, DC: The Institute for Higher Education Policy, 2000, s.20.

${ }^{65}$ Ena M. Palloff ve Keith Pratt, Lessons from the Cyberspace Classroom: The Realities of Online Teaching, San Francisco: Jossey-Bass, 2001, s.2.

${ }^{66}$ Picciano ve Seaman, $K-12$ Online, s.18.

${ }^{67}$ Weigel, "E-Learning and the Tradeoff", s.10.

${ }^{68}$ Tatana M. Olson ve Robert A. Wisher, "The Effectiveness of Web-Based Instruction: An Initial Inquiry”, International Review of Research in Open and Distance Learning, 3/2 (2002), s.11.
} 
Türkiye'de ve pek çok ülkede dijital araçlara erişim ve bu araçları kullanabilme yeterlikleri açısından öğretmenler arasında önemli farklar bulunmaktadır. Bu farklılıklar okulun sahip olduğu kaynaklar, öğrencilerin dijital araçlara erişim durumu ve kullanma yeterlikleri, okulun ve öğrencilerin sosyo-ekonomik profili, öğretmenlerin uzaktan eğitim sürecini nasıl geçirdiğini önemli ölçüde etkilemektedir. Özellikle dezavantajlı bölgelerde ve okullarda görev yapan öğretmenler bu süreçte daha fazla zorlukla karşılaşmaktadırlar. Yeterli teknolojik becerilere sahip olan öğretmenler tüm öğrencilere iletişim kanalları aracılığıyla ulaşabilse bile uzaktan eğitim bazı yaş grupları, sınıf seviyeleri, dersler ve öğrenciler için yetersiz kalabilmektedir. Öğrencilerin katılımını ve motivasyonunu sağlamak, öğrenmeyi takip etmek, öğrencilere uzaktan destek olmak için öğretmenlerin farklı yöntemler kullanması ve daha fazla çaba harcaması gerekmektedir. ${ }^{69}$

\section{Çevrim Icçi Eğitimde Ölçme ve Değerlendirme}

Uzaktan öğrenmenin etkililiği, nitelikli öğrenme sonuçlarıyla ölçülmelidir. Öğretim programları ve yetkin eğitmenler, çevrim içi eğitimdeki başarının iki önemli anahtarıdır. ${ }^{70} \mathrm{Bu}$ bağlamda çevrim içi öğrenme tasarımlarında geri bildirim ve değerlendirme mekanizmaları hayati önem taşımaktadır. Çünkü sistemin herhangi bir parçası bozulursa, tüm sistem tehlikeye girmektedir. Bu nedenle herhangi bir aksaklık meydana gelmeden önce olası sorunların tanımlanması gerekir. ${ }^{71}$ Nitelikli bir ölçme ve değerlendirme süreci için uygulanabilir bir müfredat çerçevesinde neyin bilinmesi gerektiği iyi belirlenmeli, gereksiz detaylar verilmekten kaçınılmalı ve bu konuda stratejik kararlar verilmelidir. ${ }^{72}$

Değerlendirme etkinlikleri, öğrenciler kurs boyunca çalışırken, uygulama aşamasında birim birim, modül modül, devam eden "biçimlendirici" (formative) test ve derecelendirmeyi kapsamaktadır. Buna ek olarak, belirlenen kurs materyalleri ve uygulama süreçlerinin etkililiğini değerlendirmek için ara sıra yapılan incelemeleri de içermektedir. Bu biçimlendirici değerlendirmenin sonuçları, analiz, tasarım veya geliştirme süreçlerini iyileştirme söz konusu olduğunda yardımcı olacaktır. Öğrenci testlerinin sonuçları tasarıma müdahale ihtiyacı söz konusu olduğunda, kaynak olarak kullanılmalıdır. Kursun sonunda yapılan özet değerlendirme, gelecekte karşılaşılabilecek sorunlar hakkında ipuçları sunabilmekte ve iyileştirme müdahalelerine yol gösterebilmektedir (Moore ve Kearsley, 2012, s. 99). ${ }^{73}$

Covid-19 pandemisi sürecinde uzaktan eğitimin ölçme ve değerlendirme uygulamalarının geçerlik ve güvenirlik düzeylerine yönelik bazı şüpheler söz konusudur. $\mathrm{Bu}$ süreçte daha çok sonuç odaklı ölçme ve değerlendirme yaklaşımlarına odakla-

\footnotetext{
${ }^{69}$ Gamze Çetinkaya Aydın, "COVID-19 Salgını Sürecinde Öğretmenler”, erişim 9 Eylül, 2020, https://tedmem.org/covid-19/covid-19-salgini-surecinde-ogretmenler.

${ }^{70}$ Theodore C. Smith, "Fifty-One Competencies for Online Instruction", The Journal of Educators Online, 2/2 (2005), s.1.

${ }^{71}$ Moore ve Kearsley, Distance Education, s.19.

72 Andrew Miller, "Summative Assessment in Distance Learning", https://www.edutopia.org/article/ summative-assessment-distance-learning. (erişim 10.08.2020).

${ }^{73}$ Moore ve Kearsley, Distance Education, s.99.
} 
nılarak, süreç odaklı yaklaşımlara yeterince odaklanılmadığı görülmektedir. Yalnızca ödev verilerek yapılan değerlendirmeler de uzmanların eleştirilerine konu olmaktadır. $^{74}$

\section{Dezavantajlı Aile Çocuklarının Eğitime Erişimi}

Çevrim içi öğrenme yöntemlerinin kullanılabilirliği, öğrencilere yönelik ders seçimleri açısından bazı temel dersleri sağlamak için önemlidir. Kırsal veya dezavantajlı bölgelerde fen, matematik ve yabancı diller gibi yüksek talepli ders alanlarındaki öğretmenlerin yetersizliği ciddi bir sorun oluşturabilmektedir. Bu tür uzaktan eğitim yöntemleri ile eğitim hizmetlerine uzak bölgelerdeki dezavantajlı öğrencilerin eğitime erişimi sağlanabilmektedir. ${ }^{75}$ Dünyadaki bazı ülkelerin açık ve uzaktan eğitim sistemleri aynı zamanda fiziksel ve işitme engelli öğrenciler, görme engelli kişiler ve cezaevi mahkûmları gibi dezavantajlı gruplara da eğitim fırsatları da sunmaktadır. ${ }^{76}$

Uzaktan eğitim ve diğer dijital çözümler Covid-19 ile başa çıkmanın en iyi yolu olarak görülmekle birlikte, bu yöntemlerin eğitimsel eşitsizliği artırma riskinin bulunduğu da bilinmektedir. Birleşmiş Milletler Çocuklara Yardım Fonu (UNICEF), dünya genelinde en az 463 milyon çocuğun Covid-19 pandemisi döneminde uzaktan eğitime erişimi olmadığını açılamıştır. ${ }^{77}$ Uzaktan eğitime erişemeyen çocuk sayısı anaokulu seviyesinde 120 milyona çıkarken, bu rakam ilkokul seviyesinde 217 milyon, ortaokul seviyesinde 78 milyon, lise seviyesinde 48 milyona ulaşmıştır. Öğrencilerin aynı düzeyde dijital erişime, bilgisayarlara ve internet bağlantılarına sahip olmamaları nedeniyle, politika yapıcıların öğrenci grupları arasındaki bu farklılıkları göz önünde bulundurmaları gerekmektedir. ${ }^{78}$ e-öğrenme konusundaki ilerlemelerin, eğitim açısından dezavantajlı grupları geride bırakmamasına özen gösterilmelidir. ${ }^{79}$ Büyük olasılıkla eğitim düzeyi yüksek olan ve çevrimiçi kaynaklara daha kolay erişebilen ve kullanabilen aileler için öğrenme firsatlarına erişim bu süreçte daha kolay görünmektedir. Çeşitli bağlantı ve cihazlarla, öğrenme için yapılandırılmış durumlardan yararlanmaya devam edebileceklerdir. Ancak bu koşullardan yoksun olan birçok çocuk için fiziksel uzaklaşma süresi, sınırlı öğrenme imkânları ile sonuçlanabilir. ${ }^{80}$

\section{Tartışma ve Sonuç}

Uzaktan eğitimin genellikle en yaygın kullanımı olarak karşımıza çıkan e-öğrenme ve çevrim içi öğrenme, Covid-19 pandemisi sürecinde "sosyal mesafe" kuralına en uygun eğitim yöntemleri olarak gündeme gelmekte ve pek çok ülke tarafından ter-

\footnotetext{
${ }^{74}$ Bay, "Covid-19 Sürecinde".

${ }^{75}$ Picciano ve Seaman, K-12 Online, s.18.

76 “Kampüste Olanaklar: Engelli Öğrenci Olanakları”, Anadolu Üniversitesi, erişim 29 Temmuz, 2020b, https://www.anadolu.edu.tr/kampuste-yasam/kampuste-olanaklar/engelli-ogrenci-olanaklari.

77 “Çocukların En Az Üçte Biri Uzaktan Eğitime Katılamıyor”, Birleşmiş Milletler Çocuklara Yardım Fonu (UNICEF), erişim 9 Eylül, 2020, https://www.unicefturk.org/yazi/koronavirus_egitimeerisim.

${ }^{78}$ Moreno ve Gortazar, "Schools' Readiness".

${ }^{79}$ Broom, "The World Economic".

${ }^{80}$ Reimers, "What the Covid-19".
} 
cih edilmektedir. Bu araştırmanın amacı, okullaşma sürecinde uzaktan evde eğitime geçiş sürecini incelemektir. Bu bağlamda söz konusu literatür incelenmiş ve dikkat geçen ve önemli noktalar derlenmiştir.

Pandemi öncesinde 1960'lı yıllarda uzaktan eğitimi bir türü olarak Amerika'da başlayan "evde eğitim" hareketi, okullaşma sürecinde öğrencilerin teknoloji destekli eğitim tasarımları ihtiyacını doğurmuştur. ${ }^{81}$ Ülkelerin teknolojik imkânlarına paralel olarak tarihsel süreç içerisinde gelişim gösterdiği bilinen uzaktan eğitim uygulamaları, Finlandiya, İspanya, Almanya ve Türkiye gibi ülkelerde başarılı bir şekilde uygulanmaya devam etmektedir. ${ }^{82}$ İlk ortaya çıktığı yıllarda mektupla öğretim, daha sonra radyo ve televizyon teknolojilerine dayalı yayınlar aracılığıyla yapılan eğitim tasarımları, zamanla açık öğretim kurumları bünyesinde teknoloji destekli ve internet tabanlı bir yapıya kavuşmuştur. ${ }^{83}$ Bu yapıları en iyi şekilde geliştiren ülkeler, pandemi sürecinde eğitim hizmetlerini sunmada daha aktif rol oynamışlardır. Ülkemizde MEB'in hizmetlerini sürdürmesinde ve bu hizmetleri başta öğrenci ve öğretmen olmak üzere tüm eğitim paydaşlarına iletmesinde EBA portalı önemli bir yer tutmuştur. ${ }^{84}$ Anadolu Üniversitesinin bu alandaki uluslararası düzeydeki deneyimleri de oldukça önemlidir. ${ }^{85}$

Teknoloji destekli eğitim yöntemleri tasarlanırken öğrenme çıktılarının hazırlanması ve açıkça belirtilmesi, ünitelerin tasarlanması, kurs materyallerinin içeriğe uygun şekilde düzenlenmesi, geri bildirim, ölçme ve değerlendirme süreçlerinin yapılandırılması ve bu sonuçların sistemi geliştirme ve iyileştirme amacıyla kullanılması gerekmektedir. ${ }^{86}$ Söz konusu süreçlerin eğitim kademelerine göre farklılaştırılması kritik bir öneme sahiptir. Okul öncesinde ekran başında uzun oturma süreleri önerilmemekle birlikte, ilköğretim ve ortaöğretimde çevrim içi ve yüz yüze eğitimin birlikte yer aldığı harmanlanmış tasarımlara ihtiyaç duyulmaktadır. ${ }^{87}$ Yükseköğretim düzeyinde uygulanması daha uygun bir yöntem olarak görülmektedir. Yine de tüm öğrenmelerin sosyal ve kültürel bağlamdan etkilendiği göz ardı edilmemelidir. ${ }^{88}$ Öğrenciler çoğu zaman, sözlü olmayan ipuçları ve sosyal varlık eksikliği nedeniyle iletişimlerinde kendilerini güvensiz izole hissedebilmektedirler. ${ }^{89}$

Uzaktan eğitimde sosyalleşme süreçlerinin yanı sıra eğitime erişim durumları da sıklıkla endişe duyulan konular arasında yer almaktadır. Çünkü okul müfredatına yönelik eğitim, aileler veya öğretmenler tarafından ev ortamında takip edilmektedir. ${ }^{90}$ Uzaktan eğitimde, dijital paradoks kaçınılmazdır. Dünya genelinde yapılan

\footnotetext{
${ }^{81}$ Lyman, "Homeschooling: Back", s.5.

${ }^{82}$ Moore ve Kearsley, Distance Education, s.244-267.

${ }^{83}$ Gunawardena ve McIsaac, "Distance Education”, s.356.

${ }^{84}$ Özer, "Educational Policy", s.1126.

85 "Kurumsal: Hakkında".

${ }^{86}$ Moore ve Kearsley, Distance Education, s.120-121.

${ }^{87}$ Picciano ve Seaman, K-12 Online, s.19.

${ }^{88}$ Heng-Yu Ku ve Linda L. Lohr, "A Case Study of Chinese Students' Attitudes toward Their First Online Learning Experience", Educational Technology Research and Development, 51/III (2003), s.100.

${ }^{89}$ Zuochen Zhang ve Richard F. Kenny, "Learning in an Online Distance Education Course: Experiences of Three International Students", International Review of Research in Open and Distance Learning, 11/1 (2010), s.27.

${ }^{90}$ Collom, "The Ins and Outs", s.311.
} 
araştırmalar, Covid-19 sırasında ve gelecekte okulların belli dönemlerde kapanmasına yönelik herhangi bir ihtiyaç duyulduğunda, çevrim içi öğrenmenin hem öğrenme eşitsizliklerini azaltma hem de paradoksal olarak onları şiddetlendirme potansiyeli olduğunu ifade etmektedir. ${ }^{91}$ Bu nedenle, okul faaliyetlerinde gelecekteki herhangi bir yüz yüze eğitim hizmetlerinin kesintisi sırasında, öğrenmenin sürekliliğini sağlamak için uzaktan öğrenmeye yumuşak bir geçiş sağlamak gerekmektedir.

Günümüzde uzaktan eğitime geçiş sürecindeki söz konusu değişiklikler bir ölçüde rahatsızlığa neden olmasına rağmen, eğitimsel yenilik örneklerini de başlatmışlardır. Fiziksel açıdan olmasa da entelektüel açıdan daha fazla akranla iletişime geçilebilmesi, tüm etkileşimlerin odaklanmış bir tasarımda sunulması, grup üyeleriyle bire bir görüşmeler ayarlama firsatına sahip olunması, kendi proje ve fikirleri üzerine çalışma imkânı sağlaması gibi pek çok avantaja da sahip olan uzaktan eğitim uygulamalar1, ${ }^{92}$ pandemi döneminde neredeyse tüm ülkelerde tercih edilen bir yöntem haline gelmiştir. Ancak Covid-19'a verilen tepkilerin dünyadaki eğitim sistemlerini nasıl etkileyeceğini değerlendirmek için henüz çok erken olmasına rağmen, bunun öğrenme deneyimleri üzerinde kalıcı bir etkisi olabileceğini gösteren işaretler mevcuttur (Tam ve El-Azar, 2020). ${ }^{93}$

\section{Kaynakça}

Amerikan Pediatri Akademisi (The American Academy of Pediatrics). "Media and Young Minds". Pediatrics. 138/5 (2016): 1-8.

Anadolu Üniversitesi. "Kurumsal: Hakkında". Erişim 29 Temmuz, 2020. https://www.anadolu.edu.tr/universitemiz/kurumsal/hakkinda.

Anadolu Üniversitesi. “Kampüste Olanaklar: Engelli Öğrenci Olanakları”. Erişim 29 Temmuz, 2020. https://www.anadolu.edu.tr/kampuste-yasam/kampusteolanaklar/engelli-ogrenci-olanaklari.

Andrade, Maureen S. "Teaching Online: A Theory-based Approach to Student Success". Journal of Education and Training Studies. $3 / 5$ (2015): 1-9.

Artino, Anthony R. "Online Learning: Are Subjective Perceptions of Instructional Context Related to Academic Success". The Internet and Higher Education. 12/3 (2009): 117-125.

Avrupa Konseyi. "COVID-19 Nedeniyle Alınan Evde Kalma Önlemleri, Kadın ve Çocuklara Karşı Şiddet Riskini Artırabilir”. Erişim 9 Eylül, 2020. https://www.coe.int/tr/web/ankara/-/covid-19-and-isolation-at-home-mayincrease-the-risk-of-violence-for-women-and-children.

Bay, Erdal. "Covid-19 Sürecinde Yüz yüze Eğitim Sorunu”. https://www.haber342.com/koseyazisi/covid-19-surecinde-yuz-yuze-egitimsorunu-yazisi-393.html. (erişim 21.09.2020).

\footnotetext{
${ }^{91}$ Moreno ve Gortazar, "Schools' Readiness".

${ }^{92} \mathrm{Ku}$ ve Lohr, "A Case Study", s.100.

${ }^{93}$ Gloria Tam ve Diana El-Azar, "The World Economic Forum-3 Ways the Coronavirus Pandemic Could Reshape Education”, erişim 13 Temmuz, 2020, https://www.weforum.org/agenda/2020/03/3-ways-corona virus-is-reshaping-education-and-what-changes-might-be-here-to-stay.
} 
Bielick, Stacey, Kathryn Chandler ve Stephen P. Broughman. Homeschooling in the United States: 1999 (NCES 2001-033). Washington, DC: National Center for Education Statistics U.S. Department of Education, 2001.

Bozkurt, Aras. “Türkiye'de Uzaktan Eğitimin Dünü, Bugünü ve Yarını”. Açıköğretim Uygulamaları ve Araştırmaları Dergisi. 3/2 (2017): 85-124.

Broom, Douglas. "The World Economic Forum-Homeschooling During the Coronavirus Pandemic Could Change Education Forever, Says the OECD". https://www.weforum.org/agenda/2020/04/coronavirus-homeschoolingtechnology-oecd/. (erişim 13.07.2020).

Calvert Eğitim. "Homeschooling Pros and Cons”. Erişim 2 Ağustos, 2020. https://www.calverteducation.com/should-i-homeschool/homeschoolingpros-and-cons.

Collom, Ed. "The Ins and Outs of Homeschooling: The Determinants of Parental Motivations and Student Achievement". Education and Urban Society. 37/3 (2005): 307-335.

Çetinkaya Aydın, Gamze. “COVID-19 Salgını Sürecinde Öğretmenler”. https://tedmem.org/covid-19/covid-19-salgini-surecinde-ogretmenler. (erişim 09.09.2020).

Dewey, John, Jo Ann Boydston ve Ralph Ross. The Middle Works of John Dewey, Volume 13, 1899-1924: 1921-1922, Essays on Philosophy, Education, and the Orient. Southern Illinois University Press, 1983.

Diker Coşkun, Yelkin. “Eğitimin İçeriği: Eğitim İzleme Raporu 2020”. Eğitim Reformu Girişimi. https://www.egitimreformugirisimi.org/egitim-izlemeraporu-2020-egitimin-icerigi/. (erişim 01.11.2020).

FernUniversitat in Hagen. "Fakultäten und Einrichtungen". Erişim 30 Haziran, 2020. https://www.fernuni-hagen.de/universitaet/fakultaeten-und-einrichtun gen.shtml.

Gökmen, Emrah. "Evde Kalınan Zaman İçerisinde Teknoloji Bağımlılığa Dikkat”. https://www.aa.com.tr/tr/bilim-teknoloji/evde-kalinan-zaman-icerisindeteknoloji-bagimliliga-dikkat-/1786067. (erişim 09.09.2020).

Green, Christa L. ve Kathleen V. Hoover-Dempsey. "Why do Parents Homeschool? A Systematic Examination of Parental Involvement". Education and Urban Society. 39/2 (2007): 264-285.

Gunawardena, Charlotte N. ve Marina S. McIsaac. "Distance Education", Handbook of Research on Educational Communications and Technology. J. Michael Spector, M. David Merrill, Jan Elen ve M. J. Bishop. New York: Springer, 2014.

Kanuka, Heather ve Dianne Conrad. "The Name of the Game: Why Distance Education Says It All". Quarterly Review of Distance Education. 4/4 (2003): 385-393.

Klusemann, D. Gies. "Contextualization and Localization in e-Content Production" Proceedings of the First International Conference on Educational Technology in Cultural Context, University of Joensuu, Finland, September 02-03, 2003. 
$\mathrm{Ku}$, Heng-Yu ve Linda L. Lohr. "A Case Study of Chinese Students' Attitudes toward Their First Online Learning Experience". Educational Technology Research and Development. 51/3 (2003): 94-102.

Laaser, Wolfram. "Economics of Distance Education Reconsidered". Turkish Online Journal of Distance Education. 9/3 (2008): 121-129.

Lyman, Isabel. “Homeschooling: Back to the Future?” Policy Analysis. 294 (1998): $1-22$.

Mader, Jackie. “Online Preschool: Does It Work?”. https://www.pbs.org/news hour/education/online-programs-are-filling-a-preschool-gap-experts-warnits-no-substitute-for-face-to-face-learning. (erişim 05.08.2020).

MEB (Millî Eğitim Bakanlığı). "Mesleki ve Teknik Açık Öğretim Okulu”. Erişim 6 Temmuz, 2020a. http://www.hbo.gov.tr/OgrenmeFirsatlari/MTAO.

MEB. “Koronavirüs Travmasına Karşı Psikososyal Destek Rehberleri”. Erişim 24 Temmuz, 2020. http://www.meb.gov.tr/koronavirus-travmasina-karsipsikososyal-destek-rehberleri/haber/20605/tr.

MEB. “Açık Öğretim Lisesi: Tarihçe”. Erişim 29 Temmuz, 2020c. http://aol.meb. gov.tr/www/okulumuz/icerik/1.

Miller, Andrew. "Summative Assessment in Distance Learning". https://www.edu topia.org/article/summative-assessment-distance-learning. (erişim 10.08.2020).

Milliyet. "Bakan Selçuk canlı yayında açıkladı! Uzaktan eğitim nasıl olacak?”. 29.08.2020. Erişim 9 Eylül, 2020. https://www.milliyet.com.tr/siyaset/sondakika-milli-egitim-bakani-ziya-selcuktan-uzaktan-egitim-aciklamasi-6292822.

Moore, Michael G. ve Greg Kearsley. Distance Education: A Systems View of Online Learning. Canada: Wadsworth Publishing, 3. bs., 2012.

Moreno, Juan Manuel ve Lucas Gortazar. “Schools’ Readiness for Digital Learning in the Eyes of Principals. An Analysis from PISA 2018 and Its Implications for the COVID19 (Coronavirus) Crisis Response". World Bank Blogs. https://blogs.worldbank.org/education/schools-readiness-digital-learnin g-eyes-principals-analysis-pisa-2018-and-its. (erişim 21.07.2020).

Olson, Tatana M. ve Robert A. Wisher. "The Effectiveness of Web-Based Instruction: An Initial Inquiry". International Review of Research in Open and Distance Learning. 3/2 (2002): 1-17.

Özer, Mahmut. "Educational Policy Actions by the Ministry of National Education in the times of COVID-19". Kastamonu Education Journal. 28/3 (2020): 11241129.

Palloff, Ena M. ve Keith Pratt. Lessons from the Cyberspace Classroom: The Realities of Online Teaching. San Francisco: Jossey-Bass, 2001.

Phipps, Ronald ve Jamie Merisotis. Quality on the Line: Benchmarks for Success in Internet-Based Distance Education. Washington, DC: The Institute for Higher Education Policy, 2000.

Picciano, Anthony G. ve Jeff Seaman. K-12 Online Learning: A Survey of U.S. School District Administrators. USA: Babson Survey Research Group, 2007. 
Pillay, Hitendra, Kym Irving ve Megan Tones. "Validation of the Diagnostic Tool for Assessing Tertiary Students' Readiness for Online Learning”. High Education Research \& Development. 26/2 (2007): 217-234.

Reimers, Fernando M. "What the Covid-19 Pandemic Will Change in Education Depends on the Thoughtfulness of Education Responses Today". https://www.worldsofeducation.org/en/woe_homepage/woe_detail/16727/\% E2\%80\%9Cwhat-the-covid-19-pandemic-will-change-in-education-dependson-the-thoughtfulness-of-education-responses-today\%E2\%80\%9D-byfernando-m-reimers. (erişim 16.07.2020).

Rena, Ravinder. "Challenges in Introducing Distance Education Programme In Eritrea: Some Observations and Implications". Turkish Online Journal of Distance Education. 8/1 (2007): 191-205.

Robinson, Marcene. "COVID-19 Lockdowns Worsen Childhood Obesity". http://www.buffalo.edu/news/releases/2020/06/009.html. (erişim 09.09.2020).

Simonson, Michael, Susan Zvacek ve Sharon Smaldino. Teaching and Learning at a Distance: Foundations of Distance Education. Charlotte, North Carolina: Information Age Publishing, 7. bs., 2019.

Smith, Theodore C. "Fifty-One Competencies for Online Instruction". The Journal of Educators Online. 2/2 (2005): 1-18.

Tam, Gloria ve Diana El-Azar. "The World Economic Forum-3 Ways the Coronavirus Pandemic Could Reshape Education". https://www.weforum. org/agenda/2020/03/3-ways-coronavirus-is-reshaping-education-and-whatchanges-might-be-here-to-stay. (erişim 13.07.2020).

T.C. Resmî Gazete. “Mektupla Öğretim Merkezi Kuruluş ve Çalışma Yönetmeliği”. Say1: 15252, 22.5.1975.

T.C. Resmî Gazete. "Yükseköğretim Kurumlan Teşkilâtı Hakkında Kanun Hükmünde Kararname”. Sayı: 17760, 20.7.1982.

UNED (Universidad Nacional de Educacion a Distancia). “Oferta de Grados Universitarios Oficiales 2020/2021”. Erişim 30 Haziran, 2020. http://portal.uned.es/portal/page?_pageid=93,1643102\&_dad=portal\&_schema= PORTAL.

UNESCO (Birleşmiş Milletler Eğitim, Bilim ve Kültür Örgütü). "Education: From Disruption to Recovery”. Erişim 13 Temmuz, 2020. https://en.unesco.org/ covid19/educationresponse.

UNESCO. "Uzaktan Eğitim Çözümlerini Planlamak için 10 Öneri”. Erişim 13 Temmuz, 2020. http://www.unesco.org.tr/Home/AnnouncementDetail/1453.

UNICEF (Birleşmiş Milletler Çocuklara Yardım Fonu). “Çocukların En Az Üçte Biri Uzaktan Eğitime Katılamıyor”. Erişim 9 Eylül, 2020. https://www. unicefturk.org/yazi/koronavirus_egitimeerisim.

Üsküdar Üniversitesi. "ÜSUZEM (Uzaktan Eğitim Uygulama ve Araştırma Merkezi) Hakkında”. Erişim 4 Ağustos, 2020. https://uskudar.edu.tr/tr/ uzaktan-egitim-uygulama-ve-arastirma-merkezi-hakkinda.

Weigel, Van. "E-Learning and the Tradeoff between Richness and Reach in Higher Education". Change. 33/V (2000): 10-15. 
YEĞİTEK (Yenilik ve Eğitim Teknolojileri Genel Müdürlügü). “EBA Nedir?”. Erişim 24 Temmuz, 2020. http://www.eba.gov.tr/\#/anasayfa.

YÖK (Yükseköğretim Kurulu). "Yükseköğretim Kurumlarında Uzaktan Öğretime İlişkin Usul ve Esaslar”. Erişim 29 Temmuz, 2020. https://www.yok. gov.tr/Documents/Kurumsal/egitim_ogretim_dairesi/Uzaktan_ogretim/yukseko gretim_kurumlarinda_uzaktan_ogretime_iliskin_usul_ve_esaslar.pdf.

Zhang, Zuochen ve Richard F. Kenny. "Learning in an Online Distance Education Course: Experiences of Three International Students". International Review of Research in Open and Distance Learning. 11/1 (2010): 17-36. 


\title{
Transition to Homeschooling during Schooling Process
}

\author{
ELIF DAȘCi SÖNMEZ / NECATI CEMALOĞLU
}

Abstract: Distance education applications enable students and teachers to realize their learning processes at the same or different times, regardless of location. The aim of this study is to examine the transition process to homeschooling in the schooling process. For this purpose, firstly the literature on the historical development of distance education has been discussed. Later, the strategies and policies followed by the Ministry of National Education were included in the conditions of the Covid-19 pandemic that the world was exposed to, and in this process, evaluations were made in the context of online learning, which is the most appropriate method for "social distance" and a type of distance education. By examining the effect of this type of education on various factors and levels of education, competencies related to online education were expressed and concerns about the access of disadvantaged family children to education were included. Inferences have been made that learning experiences during the pandemic period can have a lasting impact on education systems and that a smooth transition to distance learning is necessary to ensure continuity of learning in case face-to-face education services in schools are interrupted in the future.

Keywords: Distance education, Homeschooling, Education in Covid-19 pandemic, Coronavirus 